Management of Novel Ecosystems: Are Novel Approaches Required?

Timothy R. Seastedt ${ }^{{ }^{*}}$, Richard J. Hobbs ${ }^{2}$ and Katharine N. Suding ${ }^{3}$

1. Department of Ecology and Evolutionary Biology and INSTAAR, University of Colorado, Boulder CO $80309 *($ timothy.seastedt@colorado.edu)

2. School of Environmental Science, Murdoch University, Murdoch WA 6150 Australia

3. Ecology and Evolutionary Biology University of California-Irvine, Irvine, CA 92697 


\begin{abstract}
:
Most ecosystems are now sufficiently altered in terms of structure and function to qualify as novel systems, and this recognition should be the starting point for ecosystem management efforts. Under the emerging biogeochemical configurations, management activities are experiments, blurring the line between ecological research and management. Responses to specific management manipulations are context specific, influenced by the current status or structure of the system, and this argues for reference areas when conducting management or restoration activities. Attempts to return systems within their historical range of biotic and abiotic characteristics and processes may not be possible. Current management activities directed at removing undesirable features of novel ecosystems maintain or create new novel ecosystems. Control efforts to prevent what we do not want may not produce neutral or positive outcomes without the management activities that add desirable genetic and species diversity, or facilitate the biogeochemical characteristics that favor the abundance of desirable species. To ask managers to add proactive measures and rigorous experimental designs to their current activities is an unfunded mandate that will not occur without strong input from stakeholders and policy makers, which in turn argues for more rapid information transfer and proactive researchmanagement activities by the scientific community.
\end{abstract}




\section{In a nutshell}

* Novel ecosystems composed of new combinations of species under new abiotic conditions, are an increasing fact of life. Adaptive ecosystem management approaches need to explicitly acknowledge both the current and changing conditions of these systems.

* Old styles of management focusing on removing undesirable species or conditions from ecosystems to return them to a prior condition may no longer be sufficient in many cases.

* We need to consider and experiment with novel approaches to ecosystem management that focus on desired outcomes or trajectories rather than simply undertaking preventative or therapeutic activities. Under the transient conditions predicted to be the norm in this century, one cannot expect many, if any, finished products.

\section{Introduction}

We are in an era where historically authentic, co-evolved biotic assemblages are increasingly rare, and we instead are confronted by a greater incidence of native and introduced species living under new environments and new or altered disturbance regimes (Suding et al. 2004; Hobbs et al. 2006; Figure 1). Chapin and Starfield (1997) use the term 'novel ecosystem' in recognizing the response of the boreal forest to current and anticipated climatic changes. In an attempt to address the sustainability issues for the Alaskan forests, Chapin et al. (2006) proposed four broad policy strategies: 1) enhancing human adaptability, 2) increasing ecosystem resilience through strengthening negative feedbacks and increasing options for adaptation, 3) advocating human activities to reduce climate change, and 4) facilitating transformation to new, potentially more beneficial ecosystem conditions. We believe that similar activities are warranted across the 
globe, and here we explore some of the management considerations required to increase ecosystem resilience and facilitate desirable outcomes.

In theory, adaptive ecosystem management offers tools and procedures for dealing with correcting resilience problems (decreasing the resilience of undesirable states while enhancing resilience of desired states) and facilitating transformations from undesirable states. Such proactive activities are, however, the exception to what we see as a more common, reactionary approach to addressing the rapid transformations of our landscapes. Our message is perhaps directed more to policy makers and managers than scientists who, we believe, are in at least partial agreement with this position. In arguing that systems are in novel states, we recognize that what needs to be done or what constitutes best triage activities remains open for scientific debate. Here, we provide several examples of ‘desirable’ novel ecosystems and make several suggestions about management actions, realizing that these are neither complete nor universally applicable.

\section{Theoretical underpinnings of novel ecosystems}

The overarching theoretical framework for understanding novel ecosystems, as well as a compelling argument for the need for an adaptive management stance, comes from the Panarchy paradigm developed by Holling and colleagues (e.g., Holling 2001; Gunderson and Holling 2001). This synthesis of ecosystem and hierarchy theories recognizes that ecosystems manifest different states with different characteristics through time, with some stages much more vulnerable and less resilient to change. When a disturbance interacts with a sensitive state of the system, restructuring of the system occurs, and the extent of restructuring is influenced both by the current state of the system and the spatial scale at which the disturbance occurs. Historically, these interactions 
produced sustainable cycles. However, in the era of new climates, new and modified chemical inputs, and new species, disturbances function as the mechanism for the generation of novel ecosystems using whatever abiotic and biotic materials are at hand. Holling (2001, pg 404) concluded his overview by stating:

“...the era of ecosystem management via incremental increases in efficiency is over. We are now in an era of transformation, in which ecosystem management must build and maintain ecological resilience as well as the social flexibility needed to cope, innovate, and adapt.”

Panarchy theory does not provide a road map for policy makers and managers who have specific wants and needs. Other compatible and more intuitive conceptual models can be nested within the panarchy framework that help explain and emphasize the novel ecosystem concept and provide additional focus.

Landres et al. (1999) emphasize the significance of the magnitude and frequency of disturbance variables that drive the state and cycles of ecosystems. Managers understand that ecosystems are greatly influenced by fire, flood, disease outbreaks, etc., and many recognize the importance of these in determining ecosystem structure. Landres et al. (1999, pg 1880) defined the historical range of variability of ecosystems to mean "the ecological conditions, and the spatial and temporal variation in these conditions, that are relatively unaffected by people, within a period of time and geographical area appropriate to an expressed goal”. This goal is often the characterization of the current state of the ecosystem and landscape mosaic in terms of its biotic diversity and functional characteristics. The historical range of variability (HRV), characterized ecosystems at defined spatial and temporal scales. Landres et al. (1999) recognized that some 
human activities were a part of such systems, but in the last few centuries and particularly in the last few decades, human activities and indirect effects resulting from these activities have generated conditions to move what we consider natural ecosystems outside their historical range of variability.

\section{An era of increasingly rapid change}

The overwhelming majority of environmental scientists agree that biotic change will characterize and dominate the 21st century (Millennium Ecosystem Assessment 2005), producing both novel climates (Williams et al. 2007) and ‘no-analog futures' (Fox 2007). Our ability to respond to this change remains limited. The disciplinary nature of our educational systems and the reductionist approach to experimentation contribute to what we believe is a deleterious lag time between acquisition of scientific knowledge and its use in management applications. Current environmental problems, often resulting from past mistakes (e.g., failure to control invasives before they became regional problems, failure of maintaining fuel loads to mimic natural fire conditions, etc.) are consuming the time and budgets of managers, so that proactive management activities to deal with emerging problems are relatively rare and certainly under-funded (Hobbs et al 2003). We assume that managers do what they do to make management activities a success, but what constitutes success?

Factors moving terrestrial ecosystems outside their historical range of variability include the well-known list of carbon dioxide and atmospheric nitrogen enrichment, altered disturbance regimes, climate change, invasions, local or global extinctions (particularly of keystone species or ecosystem engineers), and fragmentation effects. The historical ecosystem, as identified by the theoretical framework discussed above, is recognized as composing a range of biotic and 
abiotic characteristics (Figure 2). Directional change caused by climate change, fire suppression, enhanced $\mathrm{CO}_{2}$, or atmospheric nitrogen deposition pushes the system outside its historical range of biogeochemical conditions. Species additions or subtractions, particularly of "important" species such as those achieving high abundance, keystone species, or ecosystem engineers, moves the system to a separate but new configuration, outside the historical range of variability. With changes in biotic composition, measurable changes in biogeochemical processes are likely (e.g., Ehrenfeld, 2003). Similarly, once a system has been removed from its historical range of variation due to abiotic changes, subsequent changes in species composition and biogeochemical cycling are almost certain. The causal mechanisms for change can be of biotic or abiotic origin, but the outcome may be very similar.

In managing novel ecosystems, the point is not to think outside the box but to recognize that the box has moved, and in the 21st century, the box will continue to move more rapidly (Harris et al. 2006). While we can usually predict the impact that the individual drivers will have on local ecosystems, the impacts of the combinations and interactions of these changes, along with the fact that the intensity of these changes are not uniform across the globe, generates substantial uncertainties. This presents a conundrum for managers and argues for a more active partnership with researchers who are now engaged in attempts to measure impacts of multifactoral changes on ecosystems. We believe there exists a compelling need to adopt a more dynamic framework that explicitly acknowledges and embraces change as a fundamental process occurring in all ecological systems. Scientists need to maintain or initiate a dialog with managers and policy makers with the premise that the ecosystems we manage have already been altered in ways that predispose them to further change and reduced resilience. The purpose of advocating the widespread existence of novel ecosystems over a more traditional approach to ecological 
management is to make an explicit statement that the focus of ecological study is not just undergoing change, but that the current systems are already transformed and are in the process of transforming further.

\section{Implications for Management}

Classical management of natural ecosystems often involves maintaining the system within the historical range of variability of abiotic and biotic drivers. Even in those ecosystems that have not experienced direct human alterations, the 'indirect effects’ of climate change, atmospheric chemistry changes, and introduced species have or will shortly transfigure these systems. Thus, traditional approaches are predicted to be unproductive because HRV conditions no longer exist or are no longer management options.

Chapin et al.'s (2006) study of changes in the boreal forest provides a model system relevant to most terrestrial systems experiencing climate warming. That study is also relevant to those systems that are also fire prone or have fire suppression issues. In the western U.S., many forests are currently in the process of being transformed by catastrophic fires or large-scale insect outbreaks, while much smaller areas are undergoing novel thinning activities in hopes of precluding the former processes (Noss et al. 2006a, b). All of these activities, in conjunction with fragmentation and road activity, facilitate the spread of non-native plant species (Rumbaitis del Rio 2006). In those forests not altered by fire suppression, historical logging and agricultural activities still affect the structure (Baker et al. 2007) and function (McLauchian et al. 2007) of these systems. In tropical or more humid forested ecosystems, landscape change, invasive species (including all trophic components: trees, defoliating insects, earthworms, and pathogens), and wholesale reductions in species and genetic diversity dominate sustainability issues. While examples of adaptive forest ecosystem management exist (e.g., Bormann et al. 2007), the amount 
of research, education, and outreach required to mitigate climate change, alone, (e.g., Chapin et al. 2006) argues that there are too many problems confronting too few managers with too few resources.

Invasive species are likely to have an increasingly important role in grassland dynamics. While invasive species can be quantified as drivers or passengers of change in communities (MacDougal and Turkington 2005), we suggest that these species are both passengers and drivers within novel ecosystems. The economic and ecological damages inflicted by invasive species in grasslands and rangelands are large, and expenditures to control these species with herbicides or other proactive management activities are also large. However, when the management focus is only on the invader, native species or even desirable non-native species may not necessarily be the beneficiaries of the management activity. For instance, in Southern California grasslands that have been previously overgrazed, control of a particularly problematic invader, artichoke thistle (Cynara cardunculus), may only be a first step in restoration when the native component has been almost completely removed (Figure 3). Within the next few years, millions of hectares of rangeland in the U.S. that are dominated by several species of invasive knapweeds (Centaurea spp.) will likely be replaced by new dominant plant species as the knapweeds are reduced in densities by biological control agents (Story et al. 2006; Seastedt et al. 2007). The few studies that have monitored vegetation response to these declines suggest that other non-native species will increase in abundance in response to the demise of the Centaurea species (Densmore and D’Antonio 2005; Bush et al. 2007; Figure 4).

\section{Managing under no-analog conditions}

In the past, managers have attempted to eliminate processes or components that violated general perceptions of desirable systems. With these new challenges, managers must re-examine 
these perceptions and develop management strategies to promote ecosystems that are both feasible and resilient. As indicated by Figure 2 and shown by an increasing number of examples, focusing on only one of these dimensions is insufficient to move the ecosystem back to its historical condition or to a desirable state, if not historic (i.e., back to dominance by the desired, pre-existing, native species). While climate change may impose limitations on the ability to move the biogeochemical configuration of ecosystems, reversing or negating trends caused by other directional drivers is possible. Under geochemical conditions that cannot be reversed without unacceptable cost, stakeholders must select from among those mechanisms that can enhance resilience and those alternatives that provide the biotic structure and ecosystem services they are willing to accept and support.

While emphasizing that 'one size does not fit all', management activities must either find species capable of persisting with the changes that result from these directional shifts or find mechanisms that can provide sufficient resilience to allow for the persistence of desired species in the face of these changes. Examples follow of non-traditional management activities that have maintained a relict, desirable native community without the continuation of a key driver, and of a novel grassland generated by a less-than-traditional restoration effort. The examples demonstrate that either biotic or abiotic manipulations can be used to generate 'what we want' under conditions outside the HRV of the preexisting systems.

1. Maintaining a relict tallgrass prairie without frequent fire: Adding an alternative negative feedback.

At the base of the Front Range of Colorado, a relict tallgrass prairie composed of thick stands of big bluestem, switchgrass, and Indian grass can be found on portions of lands owned and managed by the city of Boulder. These species generally require $800 \mathrm{~mm}$ of precipitation per 
year to maintain dominance, yet at this site they persist in an area that averages about $500 \mathrm{~mm}$ of precipitation due to local soil conditions. This grassland is arguably the rarest terrestrial ecosystem type in Colorado. The fire return interval for this region was estimated at one fire every 7-12 years (Veblen et al. 2000), and fire is viewed as essential to the maintenance of this grassland type (e.g., Knapp et al. 1998). These systems are also vulnerable to almost all of the previously discussed environmental change drivers.

Burning portions of this area is now considered unacceptable due to an adjacent, major freeway. For the last $20+$ years, a bottomland tallgrass site has been maintained by a shortduration, intensive spring grazing activity by cattle. The animals search out and consume whatever is green on these sites and avoid eating the standing dead material from the warmseason grasses. Significantly, what is green includes numerous non-native species such as Canada thistle, and a number of cool-season grasses. The cattle heavily graze the cool-season plants and trample the previous year's standing dead vegetation, exposing the soil surface to sunlight. Following the removal of the animals in late May, the trampling allows for the rapid emergence of warm season grasses into full sunlight. These species then dominate the water, light, and nutrient resources of the site. While fecal material and urine from the grazers increases plant-available nitrogen content, the timing of the fertilization activity produces a lush stand of tallgrass species instead of stimulating more nitrogen-demanding cool-season grasses or weedy species. To date, this unconventional management activity has sustained the tallgrass species, and this result is in marked contrast with traditional grazing effects observed in tallgrass prairie (e.g., Towne et al. 2005) where year-around or growing season grazing activities reduce the abundance and dominance of these plant species. 


\section{Revegetating a gravel pit: Hedging your bets with a diverse, native seed mix.}

Nearby to the site discussed above, gravel was mined from a 100 hectare bottomland site (originally a relict tallgrass area) for over forty years. State regulations demanded that the site be revegetated, and rocks from construction sites were used to refill the excavations. The topsoil used in this revegetation was that previously removed from the site prior to the extraction of gravel. The fact that much of this soil had been stockpiled for an unknown interval meant that what was returned and spread upon the surface was very different from that which was removed. Measurements of organic matter and organic nitrogen indicated that the soils on the revegetated site were characteristic of arid shortgrass steppe than a mesic, bottomland tallgrass prairie (Cherwin et al, in press).

Only native grasses were seeded onto this site in 1998. Following the seeding, the site experienced a relatively wet year (128\% of the 30 year average), while the next three years experienced $79 \%, 90 \%$, and $69 \%$ of average precipitation, respectively. Foliage production in this area was severely limited during this three-year drought. Low organic matter soils and low precipitation during the early stages of grass recovery would have doomed a restoration effort focused at rebuilding a tallgrass prairie. However, the seed mixture used nine grass species whose moisture demands spanned a $500 \mathrm{~mm}$ rainfall gradient. The plant community that emerged (Figure 5) was dominated by a warm-season plant, salt sacaton (Sporobolus airoides), a species usually abundant only in alkali or dry saline soils. Such soils, to our knowledge, do not occur naturally in our area. This single species was responsible for about half of the vegetation cover. Other warm-season grasses common in mixed-grass and shortgrass steppe provided another $25 \%$ of relative vegetation cover. What was particularly remarkable about the revegetated site was that planted species composed over $90 \%$ of the vegetation cover and the site 
appeared largely resistant to invasions by other native and non-native plants (Cherwin et al., in press).

This successful revegetation effort resulted from selecting a seed source containing representatives of short-, mixed-, and tallgrass species. Had the original soils been in place and had precipitation been adequate, a prairie dominated by tallgrass species might have emerged. Instead, a vegetation dominated by mixed-grass prairie species capable of surviving a three-year drought resulted from the activity. The diverse seed mix used by the revegetation team interacted with the climate conditions and unusual soil characteristics to select the community type and produced an impressive, albeit novel, grassland community.

\section{The bottom line}

In the first example presented above, managers used a spring-only grazing regime to maintain a tallgrass relict without frequent fire. In the second example, a low-budget soil and a creative seed mix produced a native grassland, one that contained a 'new' dominant plant species, and one largely devoid of invasive species. This grassland will now provide locally significant ecosystem services such as enhancing water quality of an adjacent stream, carbon and nitrogen sequestration as these soils increase in carbon and nitrogen content, and the area could also be used as a platform for desired species introductions, especially those that favor a low nitrogen environment. The successes of these examples involved the recognition that traditional management activities could not be used and/or were not likely to achieve management goals. In one case we have novel management maintaining a highly desirable relictual system which appears capable of persisting outside its HRV, and in the second case the managers used an 'uncertain climate seed mix' to generate a novel ecosystem that appears both drought and weed resistant. 
Management activities under novel conditions are experiments, and more proactive scientist-manager collaborations are needed to discover procedures for achieving management goals of these systems (Landres et al. 1999). Our interactions with managers suggest this group is already besieged with activities in response to the current plethora of environmental problems. Monitoring, the cornerstone of ecosystem management, has yet to achieve its appropriate level of importance. Further, managers need protection from the public and policy makers that are quick to condemn when activities designed to produce long-term results do not produce short-term benefits. Scientists provide an appropriate interface between stakeholders and managers and appropriately function as educators for both groups.

The recognition that novel ecosystems require novel management approaches and goals does not imply that all bets are off and anything goes. Our conclusions could be interpreted as espousing a free-for-all that is open to outlandish approaches and a stab-in-the-dark approach to determining and achieving desired conditions, without due consideration of the likely consequences. Clearly, this is not our intent. However, we do need to consider how to tackle this new and rapidly changing situation. Outlandish approaches are more likely if we ignore the problem than if we engage in an open debate about it. A subtle mix of hubris and humility is needed as new approaches are developed, and we would be foolish to suggest that there are simple answers.

A search for general rules that can be used to manage novel ecosystems is likely to be a long if not unproductive exercise (except for the admonition of Aldo Leopold to 'keep all of the parts’). A logical activity would be to maximize genetic, species, and functional diversity wherever possible to produce a higher probability for viability of communities and ecosystems under uncertain climate regimes. Monitoring responses to any action or inaction remains the key 
activity. In the above examples, management actions produced what were perceived as desirable outcomes by finding mechanisms that enhanced desirable system components, not by just removing or suppressing species that were not desired. If that statement appears obvious to ecologists, it has not necessarily been translated into the activities that currently dominate the time and financial budgets of land managers. In addition to enhanced monitoring, attention to a rigorous 'experimental' design, including reference areas wherever possible is appropriate if not essential to a defensible, informative, and publicly acceptable management program for novel systems. Awareness by stakeholders, policy makers and managers of the realities of current and future ecosystem changes is essential to generate management activities that have positive rather than neutral or negative outcomes. The participation of ecologists in adaptive management activities has been advocated for over a decade (e.g., Christensen et al. 1996), but this call to action deserves to be re-emphasized and strengthened due to the complexities and urgency of global environmental change issues affecting the structure and function of ecosystems. If we are to effectively manage existing and potential novel ecosystems, we need some serious thought about what the goals and approaches need to be.

\section{Acknowledgments}

We thank David Norton and Nehalem Breiter for use of their photographs. Lynn Riedel provided input on city of Boulder management activities. We thank Nehalem Breiter, Viki Cramer, and Karie Cherwin for reviewing an earlier draft of this manuscript. The subject editor and two anonymous reviewers made extensive and productive comments and suggestions that have been incorporated into the current manuscript. 


\section{References}

Baker, W.L., T.T. Veblen and R.L. Sherriff. 2007. Fire, fuels and restoration of ponderosaDouglas fir forests in the Rocky Mountains, USA. J. Biogeogr. 34: 251-269.

Bormann, B.T., R.W. Haynes, and J.R. Martin. 2007. Adaptive management of forest ecosystems: did some rubber hit the road? BioScience 57: 186-191.

Bush, R.T., T. R. Seastedt, and D. Buckner . 2007. Plant community dynamics in response to the decline of a dominant invasive plant, Centaurea diffusa, in a Colorado Grassland. Ecol. Rest. 25: $169-174$.

Butler, K.F. and T.M. Koontz. 2005. Theory into practice: Implementing ecosystem management objectives in the USDA Forest Service. Environ. Manage. 35: 138-150.

Chapin, F.S. III and A.M. Starfield. 1997. Time lags and novel ecosystems in response to transient climate change in arctic Alaska. Climatic Change 35: 449-461.

Chapin, F.S.. III, A.L. Lovecraft, E.S. Zavaleta, J. Nelson, M.D. Robards, G.P. Kofinas, S.F. Trainor, G.D. Peterson, H.P. Huntington and R.L. Naylor. 2006. Policy strategies to address sustainability of Alaskan boreal forests in response to a directionally changing climate. Proc. Nat. Acad. Sci. 103: 16637-16643. 
Cherwin, K. L. T. R. Seastedt, and K. N. Suding. in press. Effects of nutrient manipulations and grass removal on cover, species composition, and invasibility of an adventive grassland in Colorado. Rest. Ecol.

Christensen, N.L., A.M. Bartuska, J.H. Brown, S. Carpenter, C. D’Antonio, R. Francis, J.F Franklin, J.A. MacMahon, R.F. Noss, D.J. Parsons, C.H. Peterson, M.G. Turner, and R.G. Woodmansee. 1996. The report of the ecological society of America committee on the scientific basis for ecosystem management Ecol. Appl. 6: 665-691.

Denslow, J.S. and C.M. D’Antonio. 2005. After biocontrol: assessing indirect effects of insect releases. Biol. Contr. 35: 307-318.

Fox, D. 2007. Back to the no-analog future? Science 316: 823-825.

Ehrenfeld, J.G. 2003. Effects of exotic plant invasions on soil nutrient cycling processes. Ecosystems 6: 503-533.

Gunderson, L. and C.S. Holling. (eds). 2001. Panarchy: understanding transformations in human and natural ecosystems. Island Press, Washington D.C.

Harris, J.A., Hobbs, R.J., Higgs, E. and Aronson, J. 2006. Ecological restoration and global climate change. Rest. Ecol. 14: 170-176 
Hobbs, R.J., Cramer, V.A. and Kristjanson, L.J. 2003. What happens if we can't fix it? Triage, palliative care and setting priorities in salinising landscapes. Aust. J. Botany 51: 647-653.

Hobbs, R.J., S. Arico, J. Aronson, J.S. Baron, P. Bridgewater, V.A. Cramer, P.R. Epstein, J.J. Ewel, C.A. Klink, A.E. Lugo, D. Norton, D. Ojima, D.M. Richardson, E.W. Sanderson, F. Valladares, M. Vilà, R. Zamora, and M. Zobel. 2006. Novel ecosystems: theoretical and management aspects of the new ecological world order. Global Ecol. \& Biogeography 15: 1-7.

Holling, C.S. 2001. Understanding the complexity of economic, ecological, and social systems. Ecosystems 4: 390-405.

Knapp, A.K., J.M. Briggs, D.C. Hartnett and S.C. Collins, (eds.) 1998 Grassland Dynamics: Long-Term Ecological Research in Tallgrass Prairie Oxford Press, New York.

Landres, P. B., P. Morgan and F. J. Swanson. 1999. Overview of the use of natural variability concepts in managing ecological systems. Ecol Appl 9: 1179-1188.

MacDougall, A.S., and R. Turkington. 2005. Are invasive species the drivers or passengers of change in degraded ecosystems? Ecol. 86: 42-55.

McLauchian, K.K., J.M. Craine, W.W. Oswald,, R.R. Leavitt, and G.E. Likens. 2007. Changes in nitrogen cycling during the past century in a northern hardwood forest. Proc. Nat. Acad. Sci. 104: 7466-7470. 
Millennium Ecosystem Assessment. 2005. Ecosystems and Human Well-being: Synthesis. Island Press, Washington, D.C.

Noss, R.F., P. Beier, W.W. Covington, R.E. Grumbine, D.B. Lindenmeyer, J.W. Prather, F. Schmiegelow, T.D. Sisk and D.J. Vosick. 2006a. Recommendations for integrating restoration ecology and conservation biology in Ponderosa pine forest of the southwestern United States. Rest. Ecol. 14: 4-10.

Noss, R.F. J.F. Franklin, W. L. Baker, T. Schoennagel, and P.B. Moyle. 2006b. Managing fireprone forests in the western United States. Front. Ecol. Environ. 4: 481-487.

Rumbaitis del Rio, C. M. 2006. Changes in understory composition following catastrophic windthrow and salvage logging in a subalpine forest ecosystem. Can. J. For. Res. 36: 29432954.

Seastedt, T.R., D Knochel , M Garmoe, and Shana Shosky. 2007. Interactions and effects of multiple biological control insects on diffuse and spotted knapweed in the Front Range of Colorado. Biol. Contr. 42: 345-354.

Story, J. M., W. Callan, J.G. Corn, and L.J. White. 2006. Decline of spotted knapweed density at two sites in western Montana with large populations of the introduced root weevil, Cyphocleonus achates (Fahraeus). Biol. Contr. 38: 227-232. 
Suding, K.N., K. L. Gross \& G. R. Houseman. 2004. Alternative states and positive feedbacks in restoration ecology. Trend Ecol.Evol. 19: 46-53.

Towne, E. G., D. C. Hartnett and R. C. Cochran. 2005. Vegetation trends in tallgrass prairie from bison and cattle grazing. Ecol. Appl. 15: 1550-1559.

Veblen, T.T., Kitzberger, T., Donnegan, J., 2000. Climatic and human influences on fire regimes in ponderosa pine forests in the Colorado Front Range. Ecol. Appl 10: 1178-1195

Williams, J.W., S.T. Jackson, and J.E. Kutzbach. 2007. Projected distributions of novel and disappearing climates by 2100 AD. Proc. Nat. Acad. Sci. 104: 5738-5742. 


\section{List of Figures}

Figure 1. New Zealand tussock grasslands, a novel ecosystem discussed in Hobbs et al. (2006), which has been induced by cultural activities and has almost certainly crossed ecological thresholds will be difficult to reverse. (Photo by David Norton)

Figure 2. Creation of novel ecosystems via biotic or abiotic change (modified from Suding et al., 2004). The 'range of variability' as discussed by Landes et al. (1999) and the adaptive 4-phase cycle of Holling (2001) of a natural ecosystem is collapsed into the range of values found in zone A of Figure 1. I. An ecosystem is altered by directional environmental drivers (A-->B) or the addition or loss of an important species (A-->C). II.Once in the new state, (either B or C) internal restructuring due to new biotic and abiotic interactions further alters community composition via changes in species abundances or species losses, and through changes in biogeochemical interactions.

Figure 3. Cover (mean, std. error) of artichoke thistle (CYCA; a), other exotic species (b), and native species (c) prior to initiating herbicide treatments $(\mathrm{t}=0)$ and after 1,2, and 3 years of successive treatment. Sites were grouped by the degree of pre-treatment invasion of artichoke thistle. Sample size ranged from 30 sites (pretreatment and year 1) to 15 (year 3). In sites that were initially highly invaded with little native cover (triangles), control of the focal exotic has led to increase in other exotics. However, in sites with a lower level of invasion and more natives initially (squares), other exotics did not increase due to the control of artichoke thistle. In addition, recruitment of the native bunchgrass appears to be increasing at these sites (results not 
shown). Data courtesy of the Nature Reserve of Orange County, the Nature Conservancy, and the Irvine Ranch Land Reserve.

Figure 4. Effects of invasive plant removal without reseeding. Spotted knapweed, the purple flowered plant on the left, has been replaced by Dalmation toadflax, the yellow flowered plant on the right. The right side of the field had been treated with herbicides. (Photo by Nehalem Breiter)

Figure 5. Revegetation site (foreground). What was a tallgrass prairie until the 1950s and then a gravel pit until the mid 1990s is now a mixed-grass prairie. (Photo by Tim Seastedt)

fig 1

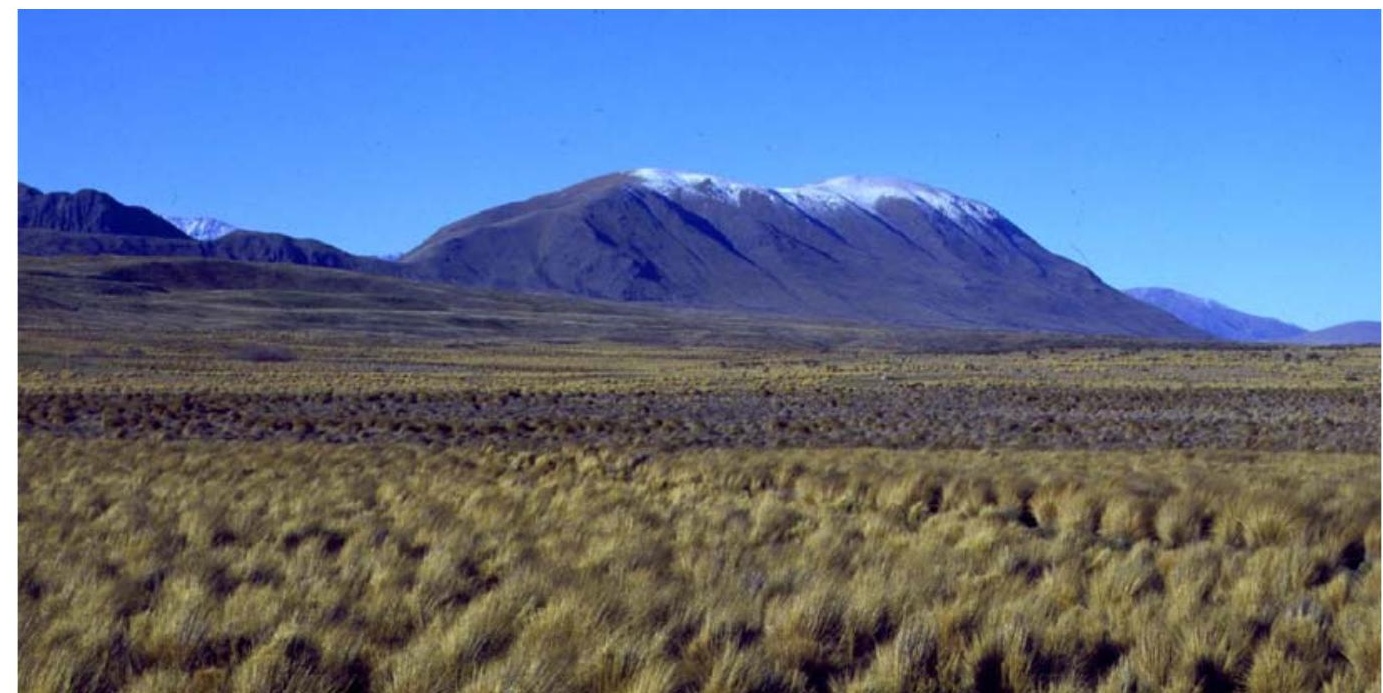


fig 2.
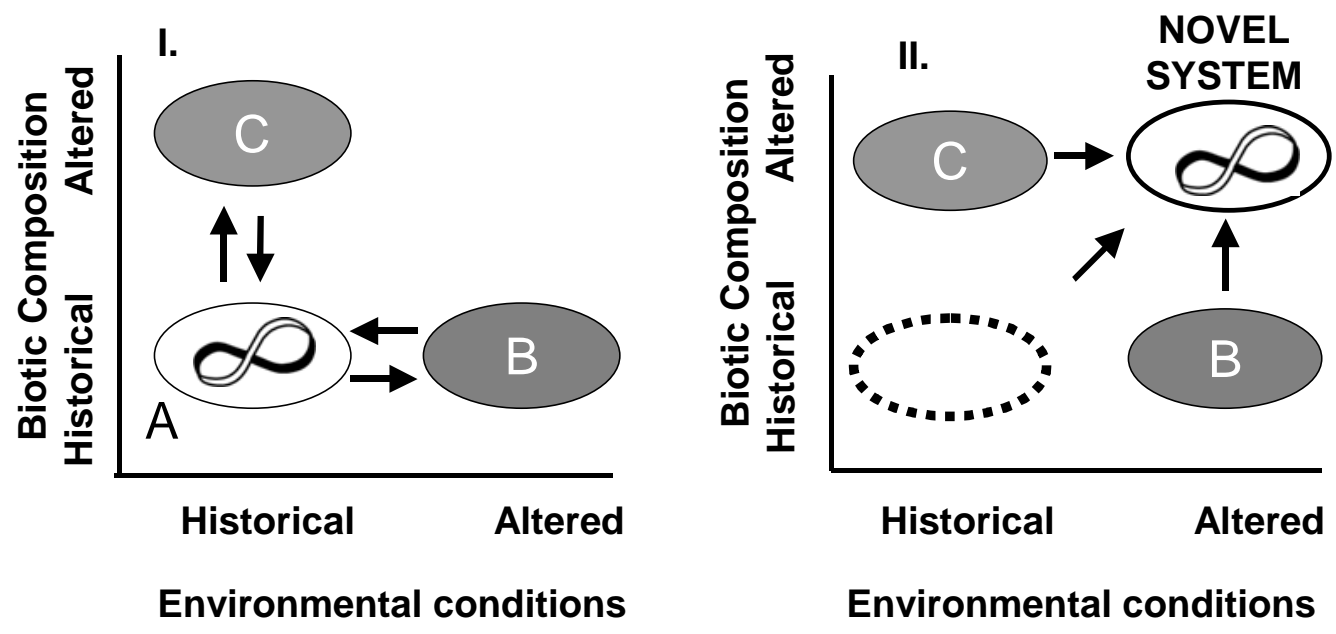


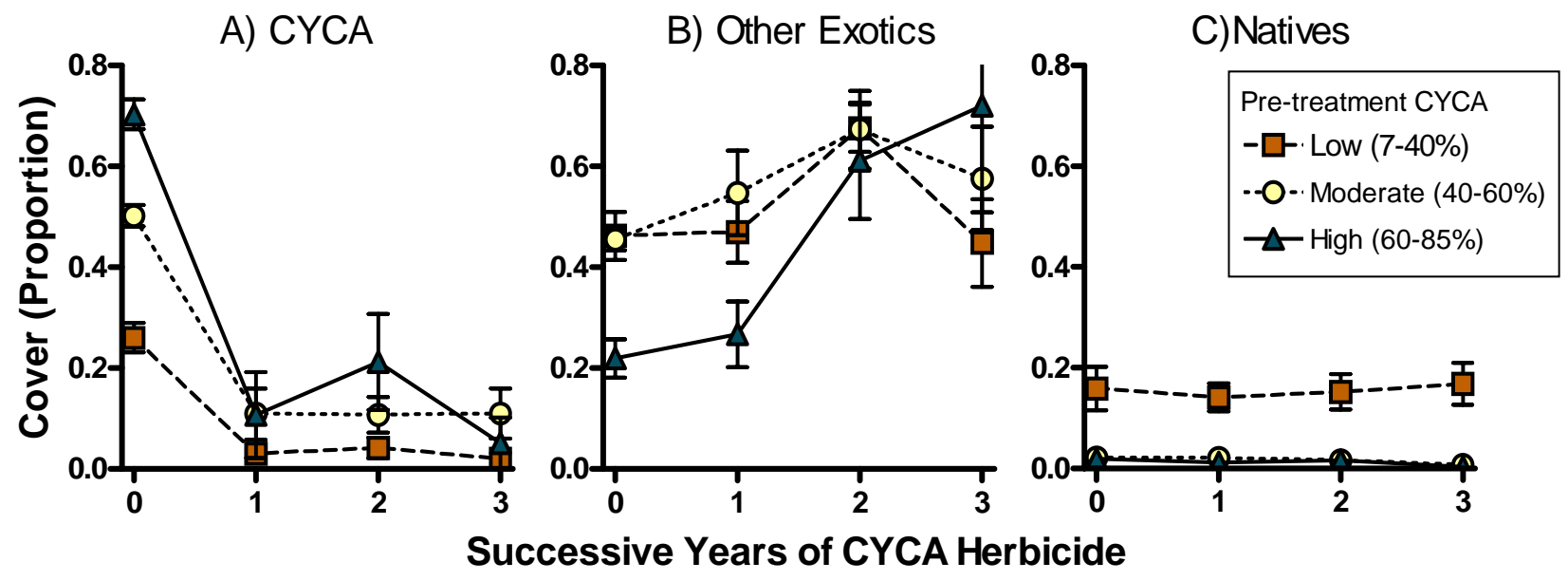

Figure 3 
fig 4.

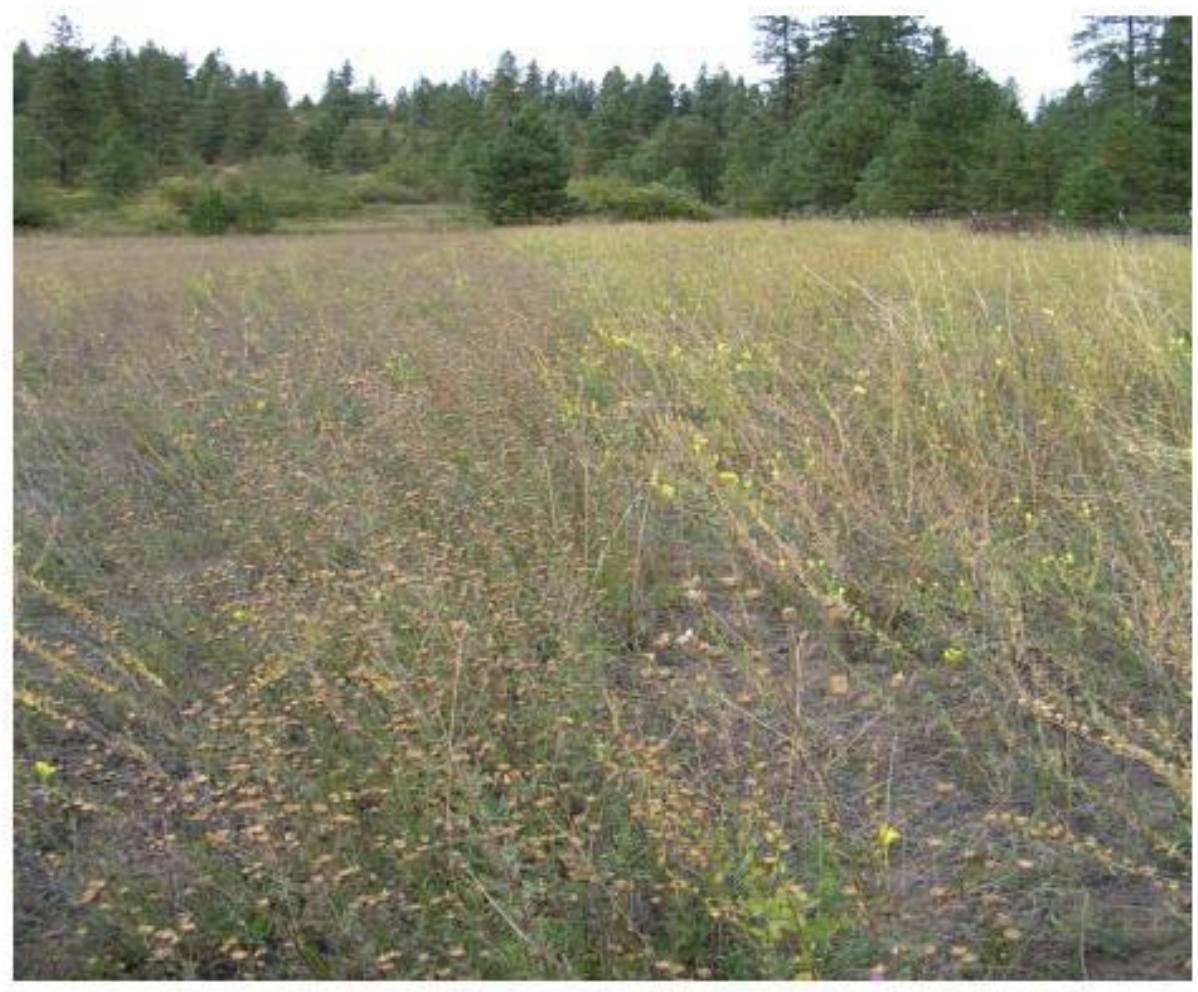


Fig. 5

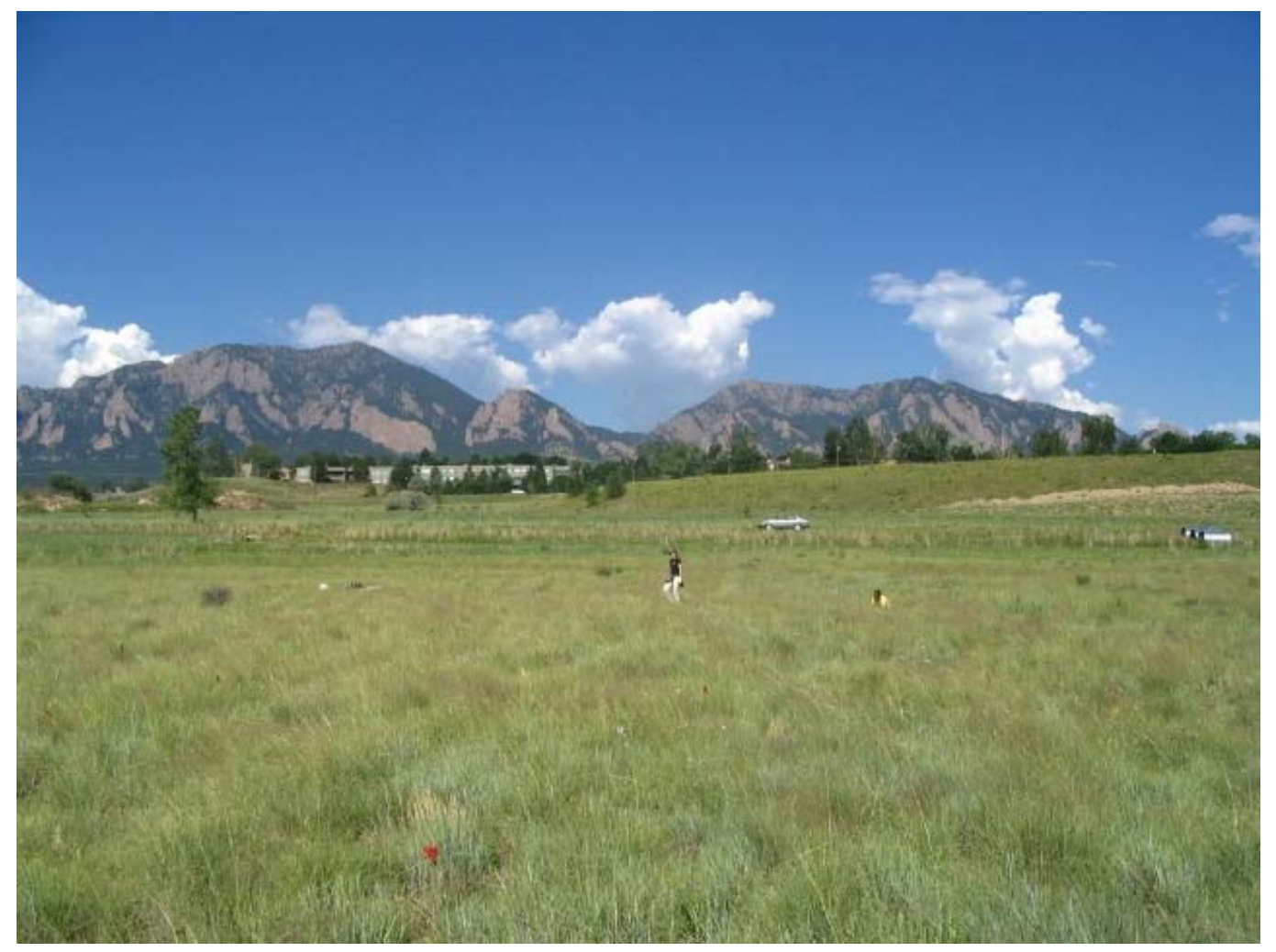

